Nota Clínica

\title{
Carcinoma tipo linfoepitelioma primario pulmonar: presentación de un caso
}

\author{
M. Luque Cabal, P. Jiménez Fonseca, Y. Fernández Pérez, J. M. Buesa Pérez
}

\section{Resumen}

Propósito: El carcinoma tipo linfoepitelioma pulmonar constituye un diagnóstico infrecuente en nuestro ámbito. Presentamos un caso en un varón de raza caucásica, con revisión de los datos publicados en la literatura.

Material y métodos: Se presenta el caso de un varón de 54 años diagnosticado de Carcinoma tipo linfoepitelioma primario pulmonar estadio IIB, tratado con cirugía y radioterapia. Tras recaida, se muestra la evolución clínica con varias líneas de quimioterapia.

Conclusiones: El carcinoma tipo linfoepitelioma pulmonar presenta una destacable quimio-radiosensibilidad, desconociéndose en el momento actual el esquema terapéutico más eficaz.

Palabras clave: Linfoepitelioma pulmonar. Caucásico. Quimioterapia.

Oncología, 2006; 29 (8):345-348

\section{Summary}

Purpose: Lymphoepithelioma-like carcinoma of the lung is a rare diagnosis in our country. We report a case in a Caucasian patient, and make a bibliographic review of the entity.

Material and methods: A 54 year old male patient was diagnosed of having a lung lymphoepithelioma-like stage IIB carcinoma, who was treated by surgery and radiotherapy. We describe the clinical evolution employing different chemotherapy combinations after tumor relapsing.

Conclusion: Lung lymphoepithelioma-like carcinoma seems highly responsive to chemoradiotherapy, but the treatment of choice has not been determined.

Key words: Lymphoepithelioma-like carcinoma. Lung. Caucasian. Chemotherapy. 


\section{Introducción}

El carcinoma tipo linfoepitelioma de pulmón fue descrito por primera vez en 1987 por Begin et al, en un paciente asiático que debutó con múltiples nódulos pulmonares ${ }^{1}$. Recibió esta denominación por su similitud histológica con el linfoepitelioma de cavum, y hasta el momento actual ha sido descrito también en otras localizaciones, como son cavidad oral, glándulas salivares, timo, estómago, piel, cérvix, vagina y vejiga $^{2}$. Constituye un diagnóstico raro, del que se han publicado poco más de 100 casos en la literatura. En su mayoría corresponden a personas de raza asiática $^{2}$, con una edad media al diagnóstico entre los 47 y 58 años $^{2-6}$, según las series. Presentamos un caso en un paciente de raza caucásica, que constituye uno de los pocos casos descritos en nuestro país ${ }^{7,8}$.

\section{Caso clínico}

Se trata de un paciente de 54 años, con historia de tabaquismo abandonado 12 años antes (20 paquetes-año) y espondilitis anquilopoyética, que ingresó en nuestro hospital en Marzo de 2002 por cuadro sugestivo de infección respiratoria y hemoptisis. En la exploración física, incluyendo exploración del área farino-laríngea, analítica general y espirometría al ingreso no se encontraron hallazgos de interés. En la radiografía de tórax se observó una masa en el segmento posterior del lóbulo superior derecho (Figura 1), que en la Tomografía Computerizada (TC)

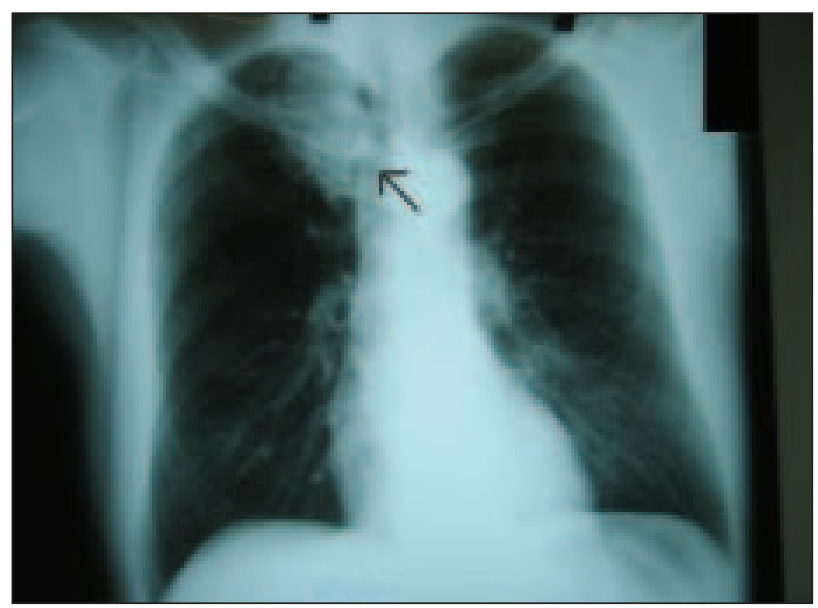

Figura 1. Radiografía póstero-anterior de tórax de marzo de 2002, en la que se ve una masa pulmonar situada en el lóbulo superior derecho. medía 4,4 x 3,8 cm y parecía afectar la pleura. A nivel abdominal el estudio fue normal y las citologías de esputo resultaron negativas. Se practicó una broncoscopia, en la que la lesión apareció en la localización descrita, bien delimitada y de color rojobrillante. Ante el fácil sangrado de la tumoración, no se practicó punción. El 11/04/02 se realizó una disección extrapleural y lobectomía superior derecha, con resección de adenopatías hilio-mediastínicas. La pieza quirúrgica fue informada como tumor macroscópico de $5 \times 4 \times 4 \mathrm{~cm}$, que histológicamente correspondía a un carcinoma de célula grande poco diferenciado variante linfoepitelioma-like (Figura 2). La pleura parietal estaba infiltrada, y las adenopatías resecadas fueron negativas para invasión tumoral, por lo que se estadió como T3N0M0 (IIb).

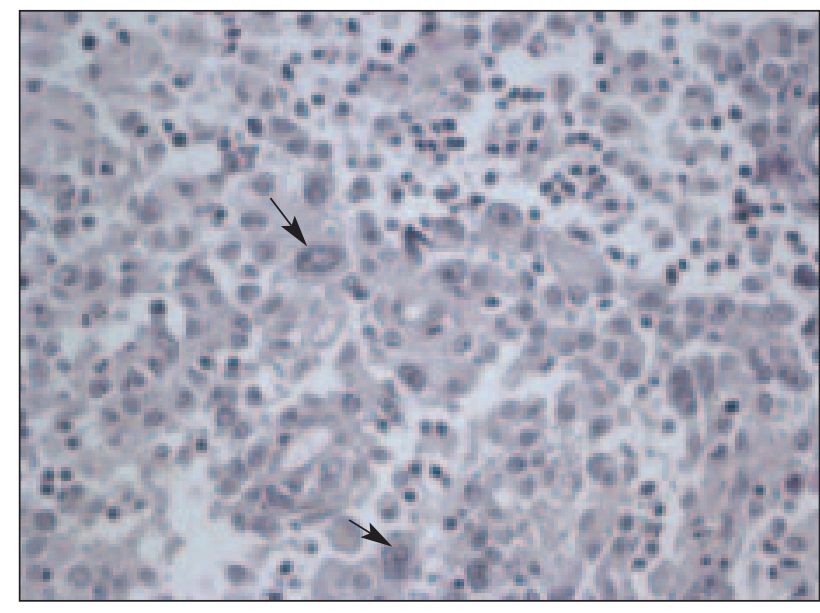

Figura 2. (x 100) Células tumorales con marcada atipia nuclear, $\mathrm{y}$ varios nucleolos, rodeadas de un infiltrado linfocitario.

Entre julio y septiembre de 2002 recibió radioterapia (RT) complementaria a nivel de mediastino y ápex pulmonar derecho (46 Gy, con sobreimpresión de 20 Gy en área de contacto de la masa con la pleura). De noviembre/2002 a mayo/2003, consultó en varias ocasiones por clínica de pirosis y dispepsia. Fue diagnosticado de reflujo gastroesofágico, hernia de hiato y gastritis antral por Helicobacter pylori, por lo que realizó tratamiento antibiótico erradicador. En Junio de 2003, debido a la persistencia de la clínica, acompañada de dolor abdominal y adelgazamiento de $10 \mathrm{~kg}$ en esos 6 meses, se realizó Ecografía abdominal y TC, donde se observó distensión gástrica y dilatación del bulbo duodenal secundarios a una masa retroperitoneal en área celiaca, de 7 x $10 \mathrm{~cm}$ y adenopatías re- 
troperitoneales periaórticas de $1.5 \mathrm{~cm}$. La recidiva se confirmó por punción-aspiración con aguja fina de la masa retroperitoneal. Entre julio y septiembre de 2003 recibió quimioterapia (QT) con Taxotere $40 \mathrm{mg} / \mathrm{m}^{2}$ días 1,8 , y Gemcitabina $1250 \mathrm{mg} / \mathrm{m}^{2}$ días 1,8 cada 21 días, x 3 ciclos, dentro de ensayo clínico abierto entonces en nuestro equipo para carcinoma de pulmón no microcítico, con mejoría clínica, ganancia ponderal y respuesta parcial (RP) del $75 \%$ de la masa por TC (9/03). Como toxicidad, diarrea grado 2 tras el primer ciclo. Tras 2 ciclos más, en la TC de noviembre/2003 se objetivó enfermedad sin cambios (NC), por lo que se detuvo el tratamiento, manteniendo controles periódicos.

En enero/2004, ante empeoramiento clínico, se solicitó TC en el que apareció una progresión (PE) a nivel de la masa retroperitoneal. Se inició $2^{\mathrm{a}}$ línea con esquema utilizado en linfoepitelioma de cavum, Cisplatino $50 \mathrm{mg} / \mathrm{m}^{2}$ y Capecitabina, en vez de 5 Fluoruracilo, ante rechazo del paciente a ingresar para los tratamientos, a dosis de $2000 \mathrm{mg} / \mathrm{m}^{2}$ x 14 días. Tras 4 ciclos, con toxicidad en forma de náuseas grado 2-3, presentó RP en TC, administrándose 3 ciclos más. En TC de junio/04 se vio de nuevo PE, por lo que se comenzó $3^{\text {a }}$ línea con 4-epirrubicina 40 $\mathrm{mg} / \mathrm{m}^{2}$ días 1,8 cada 21 días, de la que se administratron 4 ciclos. Durante este periodo presentó aumento del dolor abdominal y PE en la TC, con aparición de adenopatías que comprimían la vena renal izquierda. Se inició entonces $4^{\mathrm{a}}$ línea con Etopósido $50 \mathrm{mg} \mathrm{x}$ 20 días vía oral y se administaron 3 sesiones de radioterapia paliativa de 6 Gy a nivel retroperitoneal, a pesar de lo cual no presentó mejoría clínica.

En noviembre de 2004 ingresó ante anemia, con $\mathrm{Hb}$ de 4,9 g/dl, en relación con hemorragia digestiva alta. Se transfundieron 4 concentrados de hematíes y se inició $5^{\mathrm{a}}$ línea con Vinorelbina 25 $\mathrm{mg} / \mathrm{m}^{2} / \mathrm{sem}$. Hasta Diciembre de 2004 recibió 3 ciclos, periodo durante el cual se mantuvo clínica y hematológicamente estable, no precisando nuevas transfusiones.

En diciembre de 2004 presentó nuevo empeoramiento en la sintomatología (dolor abdominal intenso, sindrome constitucional) y anemización, por lo que fue hospitalizado, objetivándose en este ingreso varios episodios de hematoquecia. Se decide, ante el mal estado general con K $30 \%$, no realizar estudios invasivos y tratamiento sintomático, siendo éxitus en febrero de 2005.

\section{Discusión}

El carcinoma tipo linfoepitelioma de pulmón (CLEP), análogo histológicamente a los descritos en otras localizaciones, se incluye actualmente en el grupo del carcinoma indiferenciado de célula grande pulmonar'. En nuestro caso, aunque al diagnóstico únicamente se realizó exploración sencilla del área ORL, debemos destacar que no se observaron en ningún momento signos clínicos ni radiológicos de tumor en nasofaringe.

A diferencia de otros subtipos, no se ha encontrado asociación con el hábito tabáquico ${ }^{2,3}$ ni predilección por uno u otro sexo ${ }^{3}$.

En su mayoría corresponden a pacientes de raza asiática, en los que se ha observado una fuerte asociación con la infección por el virus de Epstein-Barr (VEB), demostrada por hibridación in situ con RNA viral en el tejido tumoral ${ }^{10}$ o por detección de DNA viral en suero por PCR ${ }^{11}$, como ocurre en el linfoepitelioma de cavum. Esta relación, en cambio, no se ha observado en los casos publicados en pacientes caucásicos ${ }^{12}$. En nuestro paciente no fue determinado este aspecto.

En lo referente a la anatomía patológica, se trata de un carcinoma pobremente diferenciado, con apariencia sincitial de las células neoplásicas, que crecen en grupos, anastomosándose, o bien de forma difusa o "en sábana". Los núcleos contienen una cromatina granular fina y un nucleolo prominente. Existe un moderado a intenso infiltrado de linfocitos, macrófagos y células plasmáticas, en ocasiones formando folículos linfoides, que también se observa en las lesiones a distancia. Se ha descrito, en algunos casos, depósito intratumoral de amiloide, también observado en el linfoepitelioma de cavum ${ }^{3,13}$.

El diagnóstico diferencial se plantea principalmente con metástasis de un linfoepitelioma de otro origen, linfoma No-Hodgkin y otros subtipos de carcinoma pulmonar ${ }^{13}$.

Parece haber una tendencia al diagnóstico en estadios tempranos de la enfermedad, de manera que en una serie de 32 pacientes recogidos en Guangzhou, China, el $44 \%$ presentaban un estadio I, estadio II $17 \%$, estadio IIIa el $24 \%$, IIIb el $6 \%$ y IV el $9 \%{ }^{14}$. Las localizaciones metastásicas más frecuentes son los ganglios linfáticos, hueso, hígado y pulmón contralatera ${ }^{14}$, de forma similar al linfoepitelima de cavum. 
En el estudio citado anteriormente, se comparó la supervivencia de la serie de 32 pacientes con CLEP frente a 84 casos de carcinoma pulmonar no-CLEP, observándose una diferencia significativa a favor de los primeros, aunque hay que tener en cuenta que es un estudio retrospectivo.

Existen aún pocos datos acerca de cual es el tratamiento más adecuado en este tipo de tumores. Los resultados y el pronóstico de los pacientes con resección quirúrgica \pm radioterapia parecen favorables, especialmente en estadio I. En la serie de Han y cols. se objetivó una supervivencia a 2 y 5 años, del $79.9 \%$ y $53.5 \%$ respectivamente ${ }^{3,6,13,14}$.

En los casos de enfermedad más avanzada o recidivas, se han usado combinaciones de quimioterapia \pm radioterapia. El esquema más utilizado en los casos publicados es Cisplatino $100 \mathrm{mg} / \mathrm{m} 2$ día $1+5$ FU $1 \mathrm{~g} / \mathrm{m}^{2}$ días 2,3 y 4 . En una serie con 7 pacientes evaluables, aparece una tasa de RP del $71.4 \%$, con $\mathrm{PE}$ en el $28.6 \%$ restante y ninguna $\mathrm{RC}^{2}$. Obviamente, se precisan más estudios en este sentido. Otros tratamientos administrados en los casos publicados, observándose respuesta en mayor o menor grado, son Carboplatino/Paclitaxel, Carboplatino/VP16, Carboplatino/5-FU ${ }^{7}, 15-18$.

En resumen, conocemos poco del tratamiento de elección en estos tumores, siendo la cirugía el de elección si ésta es posible. Cuando se trata de un estadio inoperable, existe aparentemente una importante quimio-radiosensibilidad, aunque no conocemos todavía el esquema más idóneo.

\section{Bibliografía}

1. Begin LR, Eskandari J, Joncas J, Panasci L. Epstein-Barr virus related Lymphoepithelioma-like carcinoma of the lung. J Surg Oncol 1987; 36:280-3

2. Chan ATC, Teo PML, Lam KC, Chan WY, Chow JHS, Yim APC. Multimodality treatment of primary lymphoepithelioma-like carcinoma of the lung. Cancer 1998; 83:925-9

3. Chan JKC, Hui PK, Tsang WYW, Law CK, Ma CC, Yip TTC, et al. Primary lymphoepithelioma-like carcinoma of the lung. Cancer 1995; 76:413-22.

4. Chen F, Yan J, Lai W, Jin Y, Su I. Epstein-Barr virus-associated non-small cell lung carcinoma. Cancer 1998; 82:2334-42.

5. Ho JC, Lam WK, Wong MP, Wong MK, Ooi GC, Ip MS, et al. Lymphoepithelioma-like carcinoma of the lung: ex- perience with ten cases. Int J Tuberc Lung Dis 2004; 8:890-5.

6. Han AJ, Xiang M, Gu YY, Lin SX, Xiong M. Lymphoepithelioma-like carcinoma of the lung with a better prognosis. A clinicopathologic study of 32 cases. Am J Clin Pathol 2001; 115:841-50.

7. Barroso A, Nogueira R, Lencastre H, Seada J, Parente B. Primary lymphoepithelioma-like carcinoma of the lung. Lung Cancer 2000; 28(1):69-74.

8. Hernández A, De Miguel J, Llorente D, Pedraza F, Serrano JL, Álvarez E. Large Cell Lymphoepithelioma-like carcinoma of the lung. Arch Bronconeumol 2004;40(8): 381-3.

9. Travis WD, Colby TD, Cornin B. Histologic typing of lung and pleural-tumours - The World Health Organization (WHO). Classification of lung cancer 1999.

10. Chen F, Yan J, Lai W, Jin Y, Su I. Epstein- Barr virus-associated nonsmall cell luna carcinoma. Cancer 1998; 82: 2334-42.

11. Ngan R, Yip T, Cheng W, Chan J, Cho W, Ma V, et al. Circulating Epstein-Barr virus DNA in serum of patients with lymphoepithelioma-like carcinoma of the lung. Clin Can Res 2002; 8:986-94

12. Castro CY, Ostrowski ML, Barrios R, Green LK, Popper HH, Powel PT, Ro JY. Relationship between Epstein-Barr virus and lymphoepithelioma-like carcinoma of the lung: a clinicopathologic study of 6 cases and review of the literature. Hum Pathol 2001; 32(8):863-72.

13. Irie H, Jaklitsch M, Schoffer K, Weinstein M, Salgie R. Unusual problems in breast cancer and a rare lung cancer case. JCO 2003; 21:2220-22.

14. Han A, Xiong M, Gu Y, Lin S, Xiang M. Lymphoepithelioma-like carcinoma of the lung with a better prognosis. Am J Clin Pathol 2001; 115:841-50.

15. Abe T, Tanabe $\mathrm{Y}$, Watarabe S, Fujita N, Matsumoto N, Moriyama H, et al. Gan To Kagaku Ryoho 2004; 31(8): 1215-7.

16. Ho JC, Lam WK, Ooi GC, Lam B, Tsang KW. Chemorariotherapy for advanced lymphoepithelioma-like carcinoma of the lung. Respir Med 2000; 94(19):943-7.

17. Ho JC, Lam WK, Wong MP, Wong MK, Ooi GC, Ip MS et al. Lymphoepithelioma-like carcinoma of the lung: experience with ten cases. Int J Tuberc Lung Dis 2004; 8(7): 890-5.

18. Frank MW, Shields TW, Joob AW, Kies MS, Sturgis CD, Yeldandi A, et al. Lymphoepithelioma-like carcinoma of the lung. Ann Thorac Surg 1997; 64:1162-64. 